\title{
The most important biomarker associated with coagulation and inflammation among COVID-19 patients
}

\author{
Ling-Zhi Hong ${ }^{1} \cdot$ Zhang-Xuan Shou $^{2} \cdot$ De-Ming Zheng ${ }^{3} \cdot$ Xue Jin $^{2}$ (i) \\ Received: 8 October 2020 / Accepted: 25 February 2021 / Published online: 19 March 2021 \\ (c) The Author(s), under exclusive licence to Springer Science+Business Media, LLC, part of Springer Nature 2021
}

\begin{abstract}
Coronavirus disease 2019 (COVID-19) induced by SARS-Cov-2 can be related to coagulopathy. Also, the infection-induced inflammatory changes are found in patients with disseminated intravascular coagulopathy (DIC). The lack of previous immunity to COVID-19 has caused infection of a large number of patients worldwide and unpredictability regarding the management of the complications that appear in the course of this viral illness. Lungs are the most important target organ of the SARS-COV-2. In COVID-19 patients, acute lung injury leads to respiratory failure. However, multiorgan failure can also occur in these patients. The primary coagulopathy of COVID-19 is marked by a considerable elevation of D-dimer, ferritin, and fibrinogen degradation products. In comparison, abnormalities in platelet count, prothrombin time, and partial thromboplastin time are partly uncommon in initial presentations. Inflammatory biomarkers including CRP, LDH, and IL-6 are significantly elevated in the early stages of the disease. In this regard, inflammation-associated biomarkers and coagulation test screening, including the assessment of IL-6, CRP, LDH, D-dimer, platelet count, PT\&PTT time, ferritin, and fibrinogen levels are suggested for detecting infection by this virus. Overall, COVID-19-associated coagulopathy should be managed like other patients with critical conditions, and supportive care and thromboembolic prophylaxis should be used for severe patients.
\end{abstract}

Keywords COVID-19 · Coagulation · D-dimer

\section{Introduction}

In the 21 st century, coronaviruses have been recognized as one of the most important human pathogenic viruses that affect the World Health System and cause concern in the world [1]. Coronaviruses, which belong to the Nidovirales

Ling-Zhi Hong and Zhang-Xuan Shou equally contributed to this work.

Xue Jin

jinxue@hmc.edu.cn

1 Emergency Department, Chun'an First People's Hospital (Zhejiang Provincial People's Hospital Chun'an Branch), Hangzhou 311700, Zhejiang, China

2 Department of Pharmacy, Zhejiang Provincial People's Hospital, People's Hospital of Hangzhou Medical College, No. 158 Shangtang Road, Hangzhou 310014, Zhejiang, China

3 Infectious Diseases Department, Chun'an First People's Hospital (Zhejiang Provincial People's Hospital Chun'an Branch), Hangzhou 311700, Zhejiang, China order, are classified into four genera: alpha, beta, delta, and gamma [2]. The important human pathogenic viruses belonging to the beta genus include Severe Acute Respiratory Syndrome (SARS), Middle East Respiratory Syndrome (MERS), and the Severe Acute Respiratory Syndrome-Coronavirus-2 (SARS-Cov-2) [3]. Coronaviruses are associated with a wide range of mild to severe diseases in humans [4]. The first highly pathogenic coronavirus in humans was SARS, which was endemic in China in 2002-2003 and quickly spread to other continents. SARS caused disease in 8,098 people and 774 deaths (about 10\% mortality) [5]. In 2012, MERS caused respiratory disease in the Middle East. This virus, which its reservoir was camels, led to a total of 2458 MERS infected cases and 848 death (about 35\% mortality) [6].

In late 2019, the COVID-19 pandemic began in China, which quickly spread to all countries in the world. The causative agent of COVID-19 was the SARS Cov-2, a member of the beta-corona virus. The disease quickly became pandemic due to respiratory transmission [7]. One of the main causes of high mortality in the early months of the disease was the 
unknown pathogenesis of the disease. The pathogenesis of COVID-19 disease is complex. Due to the widespread tissue spread of the virus receptor, an infection can potentially occur in various tissues of the body [8]. Viral and cellular factors (immune system) are involved in the pathogenesis of the COVID-19 disease. Infection followed by cytokine storm leads to more severe inflammation and tissue damage [9].

The COVID-19 disease can have a wide range of symptoms from mild to severe. The most frequently mentioned demographic factors were associated with death in patients with severe COVID-19 are the male gender, higher age, and people with underlying diseases such as obesity, diabetes, cardiovascular disease, hypertension, and chronic respiratory diseases [10-12]. Mortality rates vary from 3 to $15 \%$ in different studies [13, 14]. People in the ICU had more severe illnesses and higher mortality rates [15]. In patients with COVID-19, coagulation disorders and multiple agglutinations occur in different vessels [16]. COVID-19 patients are asymptomatic in $80 \%$, have clinical symptoms in $15-20 \%$, and have very severe disease in a small percentage [17]. In the early months of diagnosis, biomarkers associated with disease severity and mortality are unknown and mortality is higher. There is no specific treatment or vaccine for this disease such that the patients are mainly given supportive therapies. Therefore, finding appropriate biomarkers that can show tissue damage is of great importance. In this process, the choice of appropriate medication will be based on the patient's condition. Coagulation disorder is one of the leading causes of death in patients with COVID-19 [16, 18]. It seems that the study of important coagulation factors can be useful in planning the timely implementation of treatment protocols $[16,19]$. This study aimed to introduce important biomarkers related to coagulation in patients with COVID-19.

\section{Innate immune response and coagulation}

The coagulation system is a host defense response against bleeding, injury, and the invasion of infectious agents such as viruses [20]. Activation of the coagulation system following a viral invasion may be a defensive response of the immune system against the causative agent and can eliminate the etiological agent by causing a clot [21]. Coagulation and innate immunity use common pathways to counteract the damage and invasion of viruses, such as factors involved in the onset of coagulation and proinflammation. High levels of interleukin-6, erythrocyte sedimentation rate (ESR), C-reactive protein (CRP), and fibrinogen, which are associated with inflammation, have been observed in COVID-19 patients [19, 21-23]. This inflammation, following activation of coagulation, is a possible cause of elevated D-dimer levels following an infectious agent. Elevated D-dimer levels are associated with increased DIC formation and eventually increased mortality among COVID-19 patients [24]. Although the exact mechanism of coagulation due to SARS-Cov-2 infection has not yet been determined, the virus appears to interfere with inflammation, coagulation, and hemostasis. Chen showed that among COVID-19 patients, infection-related biomarkers including IL-6, procalcitonin, ESR, serum ferritin, and CRP were elevated by $6 \%, 52 \%$, $85 \%, 63 \%$, and $86 \%$, respectively [25].

Among immune factors, chemokines and cytokines associated with inflammation are most important. Some studies have shown the increased expression of interleukins 1, 2, 4, $6,7,10,12$, and 17, TNF-a, Macrophage colony-stimulating factor (MCSF), and interferon-gamma (IFN- $\gamma$ ) among COVID-19 patients [26-29] and a significant decrease in the number of monocytes, lymphocytes, and especially $\mathrm{T}$ cell in ICU patients. In a study on 99 cases in Wuhan, elevated total neutrophils, IL-6, and CRP and lymphopenia were observed in $38 \%, 52 \%$, and $84 \%$, and $35 \%$ of COVID-19 patients, respectively [25]. Generally, the Th1 and cytotoxic T cells are the major immune responses against viral infections. After the presenting of antigen by antigen-presenting cells (APCs), T cell response kills the virus-infected cells. Furthermore, humoral immune response, especially neutralizing antibodies, would have the protecting role and prevention of reinfection in the future. However, the precise role of acquired immunity in COVID-19 patients is unknown. The proliferation of the virus in the cell triggers the activation of neutrophils and inflammatory macrophages. Following a virus invasion to and spread in the respiratory mucus and the other cells, the immune responses provoke and produce a cytokine storm that may result in critical conditions for COVID-19 patients [26]. Virus infection intensified various proinflammatory cytokines such as TNF-a, IL-1b, and IL-6, which elevated the expression of tissue factor and von Willebrand factor from endothelial cells and monocytes that promote platelet aggregation and initiate the clotting cascade [30]. Besides, proinflammatory cytokines can also suppress the synthesis of anticoagulants and fibrinolysis by downregulation thrombomodulin and endothelial protein $\mathrm{C}$ receptor and upregulation of plasminogen activator inhibitor-1 [16, 31].

\section{Coagulation factors among COVID-19 patients}

Coagulation is a natural process that occurs to maintain hemostasis. The most important factors involved in coagulation are platelets, endothelial cells, and coagulation factors [32]. Coagulation is activated following a severe infection. So, consuming coagulation factors [30] increases the disseminated intravascular coagulation (DIC) [33], which can lead to increased mortality (Fig. 1). Various studies have reported abnormal intravascular coagulation in the clinical findings and laboratory results of COVID-19 patients. 


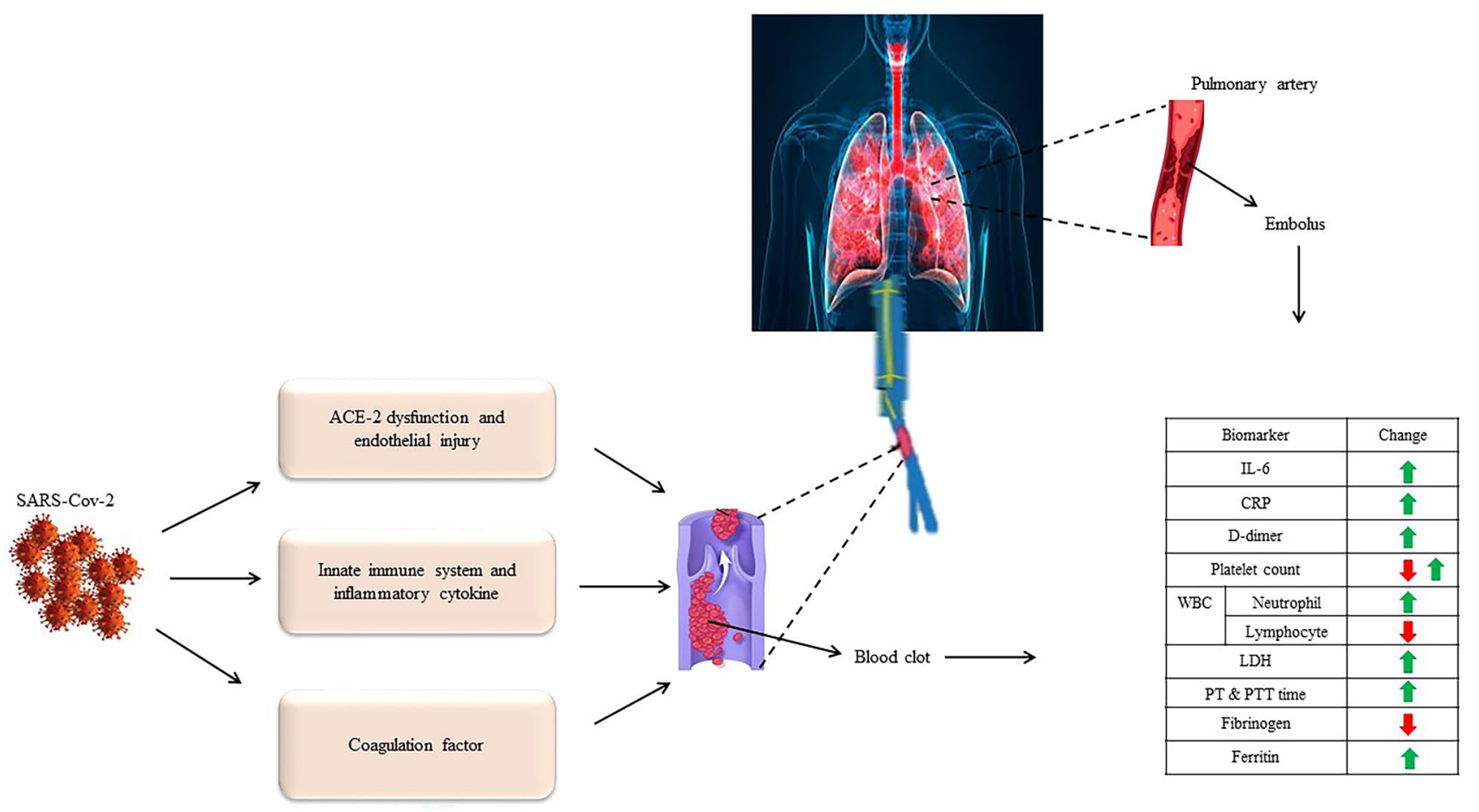

Fig. 1 In COVID-19 patients, activation of coagulation-related factors and the immune system leads to blood clots in the vessels. Activation of coagulation in the pulmonary artery causes pulmonary embolism. These factors cause changes in coagulation-related bio-

Chen studying among 99 COVID-19 patients showed that the coagulation function markers including aPTT, prothrombin (PT), and D-dimer were elevated by $6 \%, 5 \%$, and $36 \%$, respectively [25]. The combination of high D-dimer, thrombocytopenia, and prolonged coagulation tests imitate the pattern seen in DIC [34]. Pathologic findings confirm that a high level of D-dimer, PT, and thrombocytopenia in severe cases of COVID-19 lead to coagulation and were associated with multi-organ venous thromboembolism (VTE) and death $[35,36]$. Among elderly patients, those with serious underlying diseases such as heart disease, respiratory disease, diabetes, hypertension, and cancer are susceptible to SARS-COV-2 infection and often develop the severe disease [37]. The dysfunction of the coagulation system is one of the most important risk factors for severe disease and death.

\section{DIC and SIC associated with COVID-19}

Microorganisms and their components lead to the expression of tissue factors, which ultimately stimulate the immune system, release proinflammatory cytokines, and lead to activation of coagulation and inflammation [38-40]. In severe patients, infectious agents activate systemic coagulation and the inflammatory response, which probably leads to DIC. However, it seems that the DIC markers (D-dimer, CRP, PT and PTT, IL-6, fibrinogen, platelet count, $\mathrm{LDH}$, neutrophil and lymphocyte). C-reactive protein (CRP), partial thromboplastin time (PTT), prothrombin time (PT), Interleukin-6 (IL6), lactate dehydrogenase (LDH)

among COVID-19 patients has distinct differences with DIC commonly seen in patients with cancer, sepsis, or other underlying diseases accompanied by DIC [16]. Previous studies have reported severe thrombocytopenia, a much lower level of coagulation factors (especially II, V, VII, and X), and severe decline in plasma concentration of anticoagulants including protein- $\mathrm{C}$ and anti-thrombin in most patients with DIC [41]. One of the main pathological hallmarks of DIC is the increased thrombin production due to the expression of tissue factors from mononuclear cells and endothelial cells, which are induced by inflammatory cytokines such as interleukin-6 [42]. Although increased expression of IL-6 and other proinflammatory cytokines have been observed in severe COVID-19 patients, overproduction of thrombin has not been definitively proven $[16,43]$. In this regard, investigating the factors involved in thrombin production, thrombin activation, and anti-thrombin can be a helpful strategy for the treatment of these patients. Klok et al. showed that among 184 COVID-19 patients, the incidence of thrombosis was $31 \%$ [44]. Studying 449 COVID-19 patients, Tang showed that anticoagulant therapy in severe COVID-19 patients is associated with a mortality decrease [45]. Overall, it seems that thrombosis occurs with a high incidence in COVID-19 patients, and the mortality rate declines using 
the anticoagulant treatment. According to the International Society of Thrombosis and Haemostasis (ISTH), an earlier phase of sepsis-associated DIC, called "sepsis-induced coagulopathy" (SIC), and anticoagulants are beneficial in patients diagnosed with SIC criteria [46-48]. Thus, SIC seems to occur in early phases among COVID-19 patients and the diagnosis and treatment-based SIC patterns can be useful in these patients.

\section{The important biomarker among COVID-19 patients}

\section{C-reactive protein (CRP)}

CRP is a plasma protein induced by various inflammatory mediators such as IL-6 and produced by the liver [49]. Despite being nonspecific, this acute phase protein is used clinically as a biomarker for various inflammatory states. In this process, the increased level of CRP is associated with disease severity. CRP is a plasma protein induced by various inflammatory mediators such as IL- 6 and produced by the liver. Despite being nonspecific, this acute phase protein is used clinically as a biomarker for various inflammatory states. Here, an increased level of CRP is associated with the disease severity [50]. A retrospective study by Chen showed that CRP levels in COVID-19 patients who died were much higher than in patients who survived [25]. Another study by Wang showed that the increase in CRP is strongly associated with COVID-19 severity and critical condition [51]. A third retrospective cohort study by Fang Liu indicated that the CRP was elevated in $65 \%$ of COVID-19 patients on admission and elevated in $93.9 \%$ of severe COVID-19 patients [52]. All three studies suggest that CRP levels are strong biological indicators to represent the severity of the COVID-19 infection. CRP seems to be one of the first biomarkers to show physiological complications in COVID-19 patients. In addition to CRP, amyloid $\mathrm{A}$ is an acute phase protein that is increased in viral and bacterial infections. Although CRP and amyloid A are used together to screen for inflammatory disease, the use of amyloid A as a biomarker in COVID-19 patients should be further investigated [53].

\section{Interleukin 6 (IL-6)}

Studies have shown that the cytokine storm in COVID-19 patients is associated with disease severity and complications such as ARDS [54]. Interleukin-6 has been reported as the most common cytokine secreted by active macrophages. Ali's meta-analysis study showed that in severe patients, the concentration of interleukin- 6 increases by about 2.9 fold [55]. Separate studies by Liu, Qin, Ruan, and Chen showed the IL-6 level was strongly elevated in severe COVID-19 patients compared with non-severe ones [56-59].

\section{White cell count (WCC)}

White blood cells (WBCs), also known as leucocytes, are a component of blood immune cells derived from multipotent cells in the bone marrow and lymphoid tissue. These cells are divided into five major types: basophils, eosinophils, neutrophils, monocytes, and lymphocytes. Under infectious disease conditions, an increase in observed the number of WBCs, which are important biomarkers in suspecting various types of infections [60]. However, the biomarker role of WBCs in COVID-19 patients has not been confirmed. In a retrospective study, leukocytosis was found among COVID-19 patients frequently, especially among the severe cases [57]. The study by Li and Tan showed that the level of total leukocytes increased in severe patients with COVID-19 while the level of lymphocytes decreased [61, 62]. A meta-analysis study showed that $62.5 \%$ of COVID-19 patients have lymphopenia [63]. Moreover, some other studies reported that lymphopenia is more common in patients with COVID-19. Elsewhere, it was reported that low lymphocyte counts in severely ill patients may indicate a poor prognosis [64].

\section{D-dimer}

D-dimer and other Fibrin degradation products (FDPs) are the products of fibrin degradation that appears after blood clot destruction due to fibrinolysis in the blood. Blood d-dimer concentrations can help the diagnosis of thrombosis [65]. In this regard, Tang showed that d-dimer levels were higher in non-survive COVID-19 patients compared to survived ones [66]. A retrospective study by Zhang showed D-dimer on admission upper than $2.0 \mu \mathrm{g} / \mathrm{mL}$ can predict mortality in hospitals among COVID-19 patients. According to this study, the d-dimer level can be a basic and helpful biomarker to identify the patients with poor prognosis in the early stages and help to the management of COVID19 patients [67]. Various studies have reported the occurrence of the d-dimer and FDP elevation among COVID19 patients. Ning showed a higher level of d-dimer among COVID-19 patients who died [66]. Similarly, studying 1099 COVID-19 patients, Guan showed the d-dimer level was significantly elevated among non-survivors compared to survivors [68]. Fei et al. reported a higher level of d-dimer ( $1 \mu \mathrm{g} / \mathrm{mL}$ on admission) among 191 COVID-19 patients, which was associated with a high rate of mortality [69]. Huang et al. reported that COVID-19 patients with $0.5 \mu \mathrm{g} /$ $\mathrm{mL}$ or higher levels of d-dimer on admission need critical care support [70]. 


\section{Platelet count}

Studies have shown that among COVID-19 patients, severe hematologic changes lead to thrombocytopenia. A metaanalysis of 2361 patients revealed that those with severe COVID-19 infections had thrombocytopenia and thrombocytosis in 13-61\%, respectively [4]. Another meta-analysis on 1799 patients reported that severe COVID-19 patients had a significantly lower platelet count [71]. Thrombocytopenia can increase the mortality rate in severe patients. Platelet counts can indicate the severity of some infectious diseases [72]. The results of a retrospective cohort study on the 52 COVID-19 patients showed higher levels of platelets in the severe group as the most common biomarker of infection [73]. A study by Young on the 18 COVID-19 patients indicated a lower platelet count among the severe group [74]. There result is not consistent with the platelet counting, thrombocytopenia, and thrombocytosis has seen among COVID-19 patients. However, most studies have shown that thrombocytopenia occurs in severe patients.

\section{Lactate dehydrogenase (LDH)}

LDH is an intracellular enzyme found in cells of many tissues in the body, especially in the kidneys, skeletal muscle, heart, liver, RBCs, brain, and lungs. Since LDH is present throughout the body, the total LDH levels cannot be a specific indicator of a particular disease or indicate damage to a particular organ [75]. When LDH-containing cells are damaged or diseased, LDH is shed into the bloodstream and leads to an increase in its LDH levels. Under normal conditions, the lactate dehydrogenase converts pyruvate to lactate during the glycolysis cycle. Neoplastic conditions, pancreatitis, muscle injury, cell membrane damage, and liver and lung diseases such as COVID-19 stimulate the production of lactate dehydrogenase [76]. Various studies have shown that LDH levels are higher in severe COVID-19 patients compared with non-severe patients. A study on 1099 patients showed that high levels of $\mathrm{LDH}$ in these patients were associated with tissue damage and inflammation [68]. Also, high levels of LDH were associated with CT scans and significantly reflect pneumonia. LDH is not a tissue-specific marker [12]. Furthermore, it has been shown that the level of LDH is increased in COVID-19 patients, and this increase is significant in severe patients. Besides, there is accumulating evidence in using LDH as a biomarker for measuring the severity of COVID-19 disease [76].
Partial thromboplastin time (PTT) and prothrombin time (PT)

PT and PTT are coagulating system factors that characterize the coagulation of the blood. These factors can also be used for the early diagnosis of DIC [77]. Prothrombin, which is proteolytically cleaved to form thrombin, acts as a serine protease that converts fibrinogen to fibrin. High prothrombin expression is associated with increased plasma thrombin and leads to coagulation activation and thrombosis [78]. These factors are used to monitor bleeding problems. It has been reported that the treatment effect of heparin reduces blood's tendency to clot. Long et al. reported that hypercoagulation is probably seen in the early stages of COVID-19 patients. hypercoagulation is associated with disease progression and clinical outcomes [79]. Disruption of the coagulation system leads to a longer PT test time. In COVID-19 patients, prolongation of PT time is associated with disease outcome [33].

\section{Fibrinogen}

Fibrinogen is a glycoprotein produced by the liver and circulating in the blood. In tissue and vascular damage, fibrinogen is converted to fibrin by thrombin and blood clots are formed. Tang et al. reported that decreased fibrinogen and increased PT and D-dimer are associated with DIC among severe COVID-19 patients [45]. The laboratory parameters of COVID-19 patients demonstrated prothrombic diathesis in critically ill patients with extremely high fibrinogen levels [80]. The effect of COVID-19 on the coagulation cascade in vitro was examined by Giannis and Ziogas. A high expression of the procoagulant factor fibrinogen (FGB, FGG) genes in the virus-infected nuclear cells were identified [30]. A similar study by Zou et al. tested the coagulation function of 303 COVID-19 patients. The findings showed that fibrinogen levels in $5.7 \%$ of patients with moderate disease were $>7.0 \mathrm{~g} / \mathrm{L}$, compared to $19.1 \%$ with serious disease [81]. However, thrombolysis lowers fibrinogen levels in the advanced stages and increases fibrin-degradation products. As shown by Connors and Levy, if coagulation continues unchecked, it might lead to consumptive coagulopathy and bleeding [82].

\section{Ferritin}

Ferritin is an intracellular protein that contains iron and is the major form of iron stored in the cells. Although this protein is found in most tissue and organs, small amounts are secreted into the blood and are the carrier of iron. Ferritin is used as an indirect marker of the total amount of iron stored in the body [83]. Ferritin concentration increases significantly during the infection or cancerous conditions. Also, ferritin is an acute phase reactant that rises in the course of the disease [84]. Chen 
reported an increase in ferritin in 63\% of COVID-19 patients that may be associated with poor clinical outcomes [85].

\section{Management of coagulation among COVID-19 patients}

\section{Coagulation biomarker surveillance}

The immune system, ACE2 dysfunction, and coagulation factors are the significant activators in coagulation. Studies have shown that coagulation in COVID-19 patients is associated with increased heart damage and mortality rates. Therefore, it is recommended to investigate coagulation associated markers (D-dimer, ferritin, PT, aPTT, fibrinogen, and platelet count) and some inflammatory factors associated with tissue damage such as IL- 6 on admission in newly confirmed COVID-19 patients $[66,69,86]$. Biomarkers related to inflammation and coagulation should be checked regularly because of the importance of predicting the outcome and timely implementation of anti-coagulation strategies. Some of these factors associated with the development of DIC act like double-edged swords and imbalance the expression levels of these factors by increasing infectivity, tissue damage, and d-dimer and decreasing the fibrinogen. Therefore, further care should be taken in the treatment of these patients.

\section{Therapeutic strategy of COVID-19 patients}

The lungs are the most affected organs of COVID-19 patients and pneumonia-like symptoms are the most common clinical manifestations in infected patients [87]. Some patients, especially elderly men and those with an underlying disease, may experience multi-organ dysfunction and respiratory failure $[88,89]$. There is no targeted treatment currently available for SARS-COV-2 infection. Treatment regimens are largely supportive although multiple antiviral therapies are being evaluated. However, antibacterial drugs are used to prevent secondary infections [9]. In COVID-19 patients, impaired immune pathways, inflammation, and coagulation are associated with poor outcomes. So, balancing these pathways is vital. Elderly patients with underlying disease are susceptible to inflammation, vascular endothelial damage, and severe disease. Therefore, the drug should be prescribed according to the level of biomarkers related to coagulation, inflammation, and the immune system. Drug interactions should be considered to avoid drug-drug interactions that are effective in hypercoagulation.

\section{Conclusion}

The COVID-19 pandemic has disrupted medical science and management. These days, researchers are intensely looking for vaccines, and clinicians are facing new symptoms of the disease and are using new treatments to improve the outcome of the disease. Analysis of previous data indicates that coagulopathy caused by an inflammatory response to the SARS-Cov-2 infection results in coagulation and thrombosis formation and leads to worsening the condition of patients. Lack of previous immunity to COVID-19 leads to a large number of people become infected. Coagulation disorders in COVID-19 patients are associated with disease severity and mortality. COVID-19 infection interrupts the coagulation system and increases the risk of thromboembolism in various organs. Therefore, it is essential to monitor coagulation biomarkers (D-dimer, PT, aPTT, platelet count, and fibrinogen) regularly and use coagulation inhibitors in this disease.

Acknowledgements Not applicable.

Author contributions XJ: conception, design and inviting co-authors to participate. L-ZH and Z-XS: writing original manuscript draft. D-MZ: review and editing of manuscript critically for important intellectual content and provided comments and feedback for the scientific contents of the manuscript. All authors read, revised and approved the final manuscript.

Funding This work was supported by the Hangzhou Medical Technology Plan Project (No. OO20190052 to LZH).

\section{Declarations}

Conflict of interest The authors report no conflict of interest in this work.

\section{References}

1. De Wit E, Van Doremalen N, Falzarano D, Munster VJ (2016) SARS and MERS: recent insights into emerging coronaviruses. Nat Rev Microbiol 14(8):523

2. Chen Y, Liu Q, Guo D (2020) Emerging coronaviruses: genome structure, replication, and pathogenesis. J Med Virol 92(4):418-423

3. Pormohammad A, Ghorbani S, Khatami A, Farzi R, Baradaran B, Turner DL, Turner RJ, Bahr NC, Idrovo JP (2020) Comparison of confirmed COVID-19 with SARS and MERS cases-clinical characteristics, laboratory findings, radiographic signs and outcomes: a systematic review and meta-analysis. Rev Med Virol 30(4): 2112

4. Pormohammad A, Ghorbani S, Baradaran B, Khatami A, Turner R, Mansournia MA, Kyriacou DN, Idrovo JP, Bahr NC (2020) Clinical characteristics, laboratory findings, radiographic signs and outcomes of 61,742 patients with confirmed COVID-19 infection: a systematic review and meta-analysis. Microb Pathog 147:104390. https://doi.org/10.1016/j.micpath.2020.104390 
5. Hui D, Chan M, Wu A, Ng P (2004) Severe acute respiratory syndrome (SARS): epidemiology and clinical features. Postgrad Med J 80(945):373-381

6. Hui DS, Azhar EI, Kim Y-J, Memish ZA, Oh M-d, Zumla A (2018) Middle East respiratory syndrome coronavirus: risk factors and determinants of primary, household, and nosocomial transmission. Lancet Infect Dis 18(8):e217-e227

7. Chen T, Dai Z, Mo P, Li X, Ma Z, Song S, Chen X, Luo M, Liang K, Gao S (2020) Clinical characteristics and outcomes of older patients with coronavirus disease 2019 (COVID-19) in Wuhan, China (2019): a single-centered, retrospective study. J Gerontol 75(9):1788-1795

8. Zaim S, Chong JH, Sankaranarayanan V, Harky A (2020) COVID19 and multi-organ response. Curr Probl Cardiol 45(8):100618

9. Mehta P, McAuley DF, Brown M, Sanchez E, Tattersall RS, Manson JJ, Collaboration HAS (2020) COVID-19: consider cytokine storm syndromes and immunosuppression. Lancet (Lond Engl) 395(10229): 1033

10. Li Y, Xia L (2020) Coronavirus disease 2019 (COVID-19): role of chest CT in diagnosis and management. Am J Roentgenol 214(6):1280-1286

11. Bansal M (2020) Cardiovascular disease and COVID-19. Diabetes Metab Syndr 14(3):247-250

12. Li X, Xu S, Yu M, Wang K, Tao Y, Zhou Y, Shi J, Zhou M, Wu B, Yang Z (2020) Risk factors for severity and mortality in adult COVID-19 inpatients in Wuhan. J Allergy Clin Immunol 146(1):110-118

13. Rajgor DD, Lee MH, Archuleta S, Bagdasarian N, Quek SC (2020) The many estimates of the COVID-19 case fatality rate. Lancet Infect Dis 20(7):776-777

14. Szerlip M, Anwaruddin S, Aronow HD, Cohen MG, Daniels MJ, Dehghani P, Drachman DE, Elmariah S, Feldman DN, Garcia S (2020) Considerations for cardiac catheterization laboratory procedures during the COVID-19 pandemic. Catheter Cardiovasc Interv 96(3):586-597

15. Grasselli G, Greco M, Zanella A, Albano G, Antonelli M, Bellani G, Bonanomi E, Cabrini L, Carlesso E, Castelli G (2020) Risk factors associated with mortality among patients with COVID19 in intensive care units in Lombardy, Italy. JAMA Intern Med 180(10): 1345

16. Connors JM, Levy JH (2020) COVID-19 and its implications for thrombosis and anticoagulation. Blood J Am Soc Hematol 135(23):2033-2040

17. Nishiura H, Kobayashi T, Miyama T, Suzuki A, Jung S-m, Hayashi K, Kinoshita R, Yang Y, Yuan B, Akhmetzhanov AR (2020) Estimation of the asymptomatic ratio of novel coronavirus infections (COVID-19). Int J Infect Dis 94:154

18. Becker RC (2020) COVID-19 update: Covid-19-associated coagulopathy. J Thromb Thrombolysis 50(1):54-67

19. Levi M, Thachil J (2020) Coronavirus Disease 2019 Coagulopathy: Disseminated Intravascular Coagulation and Thrombotic Microangiopathy Either, Neither, or Both. In: Seminars in thrombosis and hemostasis. Thieme Medical Publishers, New York

20. Levi M, Schultz M, van der Poll T 2010. Disseminated intravascular coagulation in infectious disease. In: Seminars in thrombosis and hemostasis, (C) Thieme Medical Publishers, New York, 4:367-377

21. Antoniak S (2018) The coagulation system in host defense. Res Pract Thromb Haemost 2(3):549-557

22. Benelli G, Buscarini E, Canetta C, La Piana G, Merli G, Scartabellati A, Vigano G, Sfogliarini R, Melilli G, Assandri R (2020) SARS-COV-2 comorbidity network and outcome in hospitalized patients in Crema, Italy. Medrxiv 10:P10008

23. Sarzi-Puttini P, Giorgi V, Sirotti S, Marotto D, Ardizzone S, Rizzardini G, Antinori S, Galli M (2020) COVID-19, cytokines and immunosuppression: what can we learn from severe acute respiratory syndrome? Clin Exp Rheumatol 38(2):337-342

24. Lippi G, Favaloro EJ (2020) D-dimer is associated with severity of coronavirus disease 2019: a pooled analysis. Thromb Haemost 120(5):876

25. Chen N, Zhou M, Dong X, Qu J, Gong F, Han Y, Qiu Y, Wang J, Liu Y, Wei Y (2020) Epidemiological and clinical characteristics of 99 cases of 2019 novel coronavirus pneumonia in Wuhan, China: a descriptive study. Lancet 395(10223):507-513

26. Prompetchara E, Ketloy C, Palaga T (2020) Immune responses in COVID-19 and potential vaccines: lessons learned from SARS and MERS epidemic. Asian Pac J Allergy Immunol 38(1):1-9

27. Shi Y, Wang Y, Shao C, Huang J, Gan J, Huang X, Bucci E, Piacentini M, Ippolito G, Melino G (2020) COVID-19 infection: the perspectives on immune responses. Nature Publishing Group, Berlin

28. Xu X, Han M, Li T, Sun W, Wang D, Fu B, Zhou Y, Zheng X, Yang Y, Li X (2020) Effective treatment of severe COVID-19 patients with tocilizumab. Proc Natl Acad Sci 117(20):10970-10975

29. Liu Y, Zhang C, Huang F, Yang Y, Wang F, Yuan J, Zhang Z, Qin Y, Li X, Zhao D (2020) Elevated plasma level of selective cytokines in COVID-19 patients reflect viral load and lung injury. Nati Sci Rev 7(6):1003-1011

30. Giannis D, Ziogas IA, Gianni P (2020) Coagulation disorders in coronavirus infected patients: COVID-19, SARS-CoV-1, MERSCoV and lessons from the past. J Clin Virol 127:104362

31. Atallah B, Mallah SI, AlMahmeed W (2020) Anticoagulation in COVID-19. Eur Heart J 6(4):260-261

32. Verheul HM, Jorna AS, Hoekman K, Broxterman HJ, Gebbink MF, Pinedo HM (2000) Vascular endothelial growth factor-stimulated endothelial cells promote adhesion and activation of platelets. Blood J Am Soc Hematol 96(13):4216-4221

33. Iba T, Levy JH, Levi M, Thachil J (2020) Coagulopathy in COVID-19. J Thromb Haemost 18(9):2103-2109

34. Levi M, Thachil J, Iba T, Levy JH (2020) Coagulation abnormalities and thrombosis in patients with COVID-19. Lancet Haematol 7(6): 438

35. Tal S, Spectre G, Kornowski R, Perl L (2020) Venous thromboembolism complicated with COVID-19: what do we know so far? Acta Haematol 143(5):417-424

36. Zhai Z, Li C, Chen Y, Gerotziafas G, Zhang Z, Wan J, Liu P, Elalamy I, Wang C (2020) Prevention and treatment of venous thromboembolism associated with coronavirus disease 2019 infection: a consensus statement before guidelines. Thromb Haemost 120(6):937

37. Emami A, Javanmardi F, Pirbonyeh N, Akbari A (2020) Prevalence of underlying diseases in hospitalized patients with COVID19: a systematic review and meta-analysis. Arch Acad Emerg Med 8(1):e35

38. Jackson SP, Darbousset R, Schoenwaelder SM (2019) Thromboinflammation: challenges of therapeutically targeting coagulation and other host defense mechanisms. Blood 133(9):906-918

39. Delabranche X, Helms J, Meziani F (2017) Immunohaemostasis: a new view on haemostasis during sepsis. Ann Intensive care $7(1): 117$

40. Engelmann B, Massberg S (2013) Thrombosis as an intravascular effector of innate immunity. Nat Rev Immunol 13(1):34-45

41. Simmons J, Pittet J-F (2015) The coagulopathy of acute sepsis. Curr Opin Anaesthesiol 28(2):227

42. van der Poll T, de Jonge E (2013) Cytokines as regulators of coagulation. In: Madame Curie Bioscience Database [Internet]. Austin (TX): Landes Bioscience; 2000-2013. https://www.ncbi. nlm.nih.gov/books/NBK6207/

43. Costela-Ruiz VJ, Illescas-Montes R, Puerta-Puerta JM, Ruiz C, Melguizo-Rodríguez L (2020) SARS-CoV-2 infection: the role 
of cytokines in COVID-19 disease. Cytokine Growth Factor Rev 54:62-75

44. Klok F, Kruip M, Van der Meer N, Arbous M, Gommers D, Kant K, Kaptein F, van Paassen J, Stals M, Huisman M (2020) Incidence of thrombotic complications in critically ill ICU patients with COVID-19. Thromb Res 191:145-147

45. Tang N, Bai H, Chen X, Gong J, Li D, Sun Z (2020) Anticoagulant treatment is associated with decreased mortality in severe coronavirus disease 2019 patients with coagulopathy. J Thromb Haemost 18(5):1094-1099

46. Suzuki K, Wada H, Imai H, Iba T, Thachil J, Toh CH, SoDI C (2018) A re-evaluation of the D-dimer cut-off value for making a diagnosis according to the ISTH overt-DIC diagnostic criteria: communication from the SSC of the ISTH. J Thromb Haemost 16(7):1442-1444

47. Taylor FB, Toh C-H, Hoots WK, Wada H, Levi M (2001) Towards definition, clinical and laboratory criteria, and a scoring system for disseminated intravascular coagulation. Thromb HaemostStuttg 86(5):1327-1330

48. Gando S, Wada H, Thachil J (2013) Scientific and standardization committee on DIC of the international society on thrombosis and haemostasis (ISTH). differentiating disseminated intravascular coagulation (DIC) with the fibrinolytic phenotype from coagulopathy of trauma and acute coagulopathy of trauma-shock (COT/ ACOTS). J Thromb Haemost 11(5):826-835

49. Valkanova V, Ebmeier KP, Allan CL (2013) CRP, IL-6 and depression: a systematic review and meta-analysis of longitudinal studies. J Affect Disord 150(3):736-744

50. Gong J, Dong H, Xia SQ, Huang YZ, Wang D, Zhao Y, Liu W, Tu S, Zhang M, Wang Q (2020) Correlation analysis between disease severity and inflammation-related parameters in patients with COVID-19: a retrospective study. BMC Infect Dis 20(1):1-7

51. Ling W (2020) C-reactive protein levels in the early stage of COVID-19. Med Mal Infect 50(4):332-334

52. Liu F, Li L, Xu M, Wu J, Luo D, Zhu Y, Li B, Song X, Zhou X (2020) Prognostic value of interleukin-6, C-reactive protein, and procalcitonin in patients with COVID-19. J Clin Virol 127:104370

53. Yip TT, Chan JW, Cho WC, Yip T-T, Wang Z, Kwan T-L, Law SC, Tsang DN, Chan JK, Lee K-C (2005) Protein chip array profiling analysis in patients with severe acute respiratory syndrome identified serum amyloid a protein as a biomarker potentially useful in monitoring the extent of pneumonia. Clin Chem 51(1):47-55

54. Mahajan S, Decker CE, Yang Z, Veis D, Mellins ED, Faccio R (2019) Plc $\gamma 2 / T m e m 178$ dependent pathway in myeloid cells modulates the pathogenesis of cytokine storm syndrome. J Autoimmun 100:62-74

55. Coomes EA, Haghbayan H (2020) Interleukin-6 in COVID-19: a systematic review and meta-analysis. MedRxiv 395(10224):e35

56. Liu B, Li M, Zhou Z, Guan X, Xiang Y (2020) Can we use interleukin-6 (IL-6) blockade for coronavirus disease 2019 (COVID19)-induced cytokine release syndrome (CRS)? J Autoimmun 111:102452

57. Qin C, Ziwei MPLZM, Tao SYMY, Ke PCXMP, Shang MMPK Dysregulation of immune response in patients with COVID-19 in Wuhan, China; clinical infectious diseases; Oxford Academic. Clin Infect Dis 71(15):762-768

58. Ruan Q, Yang K, Wang W, Jiang L, Song J (2020) Clinical predictors of mortality due to COVID-19 based on an analysis of data of 150 patients from Wuhan. China Intensive Care Med 46(5):846-848

59. Chen L, Liu H, Liu W, Liu J, Liu K, Shang J, Deng Y, Wei S (2020) Analysis of clinical features of 29 patients with 2019 novel coronavirus pneumonia Zhonghua jie he he hu xi za zhi Zhonghua jiehe he huxi zazhi. Chin J Tuberc Respir Dis 43:E005-E005
60. Kermali M, Khalsa RK, Pillai K, Ismail Z, Harky A (2020) The role of biomarkers in diagnosis of COVID-19-a systematic review. Life Sci 254:117788

61. Ghasemi K, Parkhideh S, Kazemi MH, Salimi M, Salari S, Nalini R, Hajifathali A (2020) The role of serum uric acid in the prediction of graft-versus-host disease in allogeneic hematopoietic stem cell transplantation. J Clin Lab Anal 34(7):23271

62. Tan C, Huang Y, Shi F, Tan K, Ma Q, Chen Y, Jiang X, Li $\mathrm{X}$ (2020) C-reactive protein correlates with computed tomographic findings and predicts severe COVID-19 early. J Med Virol 92(7):856-862

63. Pormohammad A, Ghorbani S, Baradaran B, Khatam A, Turner R, Mansournia MA, Kyriacou DN, Idrovo J-P, Bahr NC (2020) Clinical characteristics, laboratory findings, radiographic signs and outcomes of 52,251 patients with confirmed covid-19 infection: a systematic review and meta-analysis. Microb Pathog 147:104390

64. Tan L, Wang Q, Zhang D, Ding J, Huang Q, Tang Y-Q, Wang Q, Miao H (2020) Lymphopenia predicts disease severity of COVID19: a descriptive and predictive study. Signal Transduct Target Ther 5(1):1-3

65. Wilde J, Kitchen S, Kinsey S, Greaves M, Preston F (1989) Plasma D-dimer levels and their relationship to serum fibrinogen/fibrin degradation products in hypercoagulable states. $\mathrm{Br} \mathrm{J}$ Haematol 71(1):65-70

66. Tang N, Li D, Wang X, Sun Z (2020) Abnormal coagulation parameters are associated with poor prognosis in patients with novel coronavirus pneumonia. J Thromb Haemost 18(4):844-847

67. Zhang L, Yan X, Fan Q, Liu H, Liu X, Liu Z, Zhang Z (2020) D-dimer levels on admission to predict in-hospital mortality in patients with Covid-19. J Thromb Haemost 18(6):1324-1329

68. Guan W-j, Ni Z-y, Hu Y, Liang W-h, Ou C-q, He J-x, Liu L, Shan H, Lei C-1, Hui DS (2020) Clinical characteristics of coronavirus disease 2019 in China. N Engl J Med 382(18):1708-1720

69. Zhou F, Yu T, Du R, Fan G, Liu Y, Liu Z, Xiang J, Wang Y, Song B, Gu X (2020) Clinical course and risk factors for mortality of adult inpatients with COVID-19 in Wuhan, China: a retrospective cohort study. Lancet 395(10229): 1054-1062

70. Huang C, Wang Y, Li X, Ren L, Zhao J, Hu Y, Zhang L, Fan G, Xu J, Gu X (2020) Clinical features of patients infected with 2019 novel coronavirus in Wuhan China. Lancet 395(10223):497-506

71. Lippi G, Plebani M, Henry BM (2020) Thrombocytopenia is associated with severe coronavirus disease 2019 (COVID-19) infections: a meta-analysis. Clin Chim Acta 506:145-148

72. Labarrere CA, Woods J, Hardin J, Campana G, Ortiz M, Jaeger B, Reichart B, Bonnin J, Currin A, Cosgrove S (2011) Early prediction of cardiac allograft vasculopathy and heart transplant failure. Am J Transplant 11(3):528-535

73. Yang X, Yu Y, Xu J, Shu H, Liu H, Wu Y, Zhang L, Yu Z, Fang $\mathrm{M}, \mathrm{Yu} \mathrm{T}$ (2020) Clinical course and outcomes of critically ill patients with SARS-CoV-2 pneumonia in Wuhan, China: a singlecentered, retrospective, observational study. Lancet Respir Med $8(5): 475-481$

74. Young BE, Ong SWX, Kalimuddin S, Low JG, Tan SY, Loh J, Ng O-T, Marimuthu K, Ang LW, Mak TM (2020) Epidemiologic features and clinical course of patients infected with SARS-CoV-2 in Singapore. JAMA 323(15):1488-1494

75. Holbrook JJ, Liljas A, Steindel SJ, Rossmann MG (1975) 4 lactate dehydrogenase. Enz Else 11:191-292

76. Han Y, Zhang H, Mu S, Wei W, Jin C, Xue Y, Tong C, Zha Y, Song Z, Gu G (2020) Lactate dehydrogenase, a risk factor of severe COVID-19 patients. MedRxiv 19(4):353

77. Imura Y, Terashita Z-i, Nishikawa K (1986) Possible role of platelet activating factor (PAF) in disseminated intravascular coagulation (DIC), evidenced by use of a PAF antagonist, CV-3988. Life Sci 39(2):111-117 
78. Martinelli I, Sacchi E, Landi G, Taioli E, Duca F, Mannucci PM (1998) High risk of cerebral-vein thrombosis in carriers of a prothrombin-gene mutation and in users of oral contraceptives. $\mathrm{N}$ Engl J Med 338(25):1793-1797

79. Long H, Nie L, Xiang X, Li H, Zhang X, Fu X, Ren H, Liu W, Wang Q, Wu Q (2020) D-dimer and prothrombin time are the significant indicators of severe COVID-19 and poor prognosis. BioMed Res Int 2020:1

80. Thachil J, Agarwal S (2020) Understanding the COVID-19 coagulopathy spectrum. Wiley, Hoboken

81. Zou Y, Guo H, Zhang Y, Zhang Z, Liu Y, Wang J, Lu H, Qian Z (2020) Analysis of coagulation parameters in patients with COVID-19 in Shanghai China. Biosci Trends 14(4):285-289

82. Marchandot B, Sattler L, Jesel L, Matsushita K, Schini-Kerth V, Grunebaum L, Morel O (2020) COVID-19 related coagulopathy: a distinct entity? J Clin Med 9(6):1651

83. Seckback $\mathbf{J}$ (1982) Ferreting out the secrets of plant ferritin-a review. J Plant Nutr 5(4-7):369-394

84. Stevens RG, Beasley RP, Blumberg BS (1986) Iron-binding proteins and risk of cancer in Taiwan. JNCI J Nati Cancer Instit 76(4):605-610

85. Qin Z, Zhang X, Chen Z, Liu N (2020) Establishment and validation of an immune-based prognostic score model in glioblastoma. Int Immunopharmacol 85:106636
86. Wang D, Hu B, Hu C, Zhu F, Liu X, Zhang J, Wang B, Xiang H, Cheng Z, Xiong Y (2020) Clinical characteristics of 138 hospitalized patients with 2019 novel coronavirus-infected pneumonia in Wuhan China. JAMA 323(11):1061-1069

87. Tahvildari A, Arbabi M, Farsi Y, Jamshidi P, Hasanzadeh S, Calcagno TM, Nasiri MJ, Mirsaeidi M (2020) Clinical features, diagnosis, and treatment of COVID-19 in hospitalized patients: a systematic review of case reports and case series. Front Med 7:231

88. Collange O, Tacquard C, Delabranche X, Leonard-Lorant I, Ohana M, Onea M, Anheim M, Solis M, Sauer A, Baloglu S (2020) Coronavirus disease 2019: associated multiple organ damage. In: Open forum infectious diseases. Oxford University Press US, 7:ofaa249

89. Robba C, Battaglini D, Pelosi P, Rocco PR (2020) Multiple organ dysfunction in SARS-CoV-2: MODS-CoV-2. Expert Rev Respir Med 14(9):865-868

Publisher's Note Springer Nature remains neutral with regard to jurisdictional claims in published maps and institutional affiliations. 